\title{
In Vitro Localization of Bone Growth Factors in Constructs of Biodegradable Scaffolds Seeded with Marrow Stromal Cells and Cultured in a Flow Perfusion Bioreactor
}

\author{
MANUELA E. GOMES, Ph.D., ${ }^{1-3}$ CARLA M. BOSSANO, B.S., ${ }^{3}$ CAROL M. JOHNSTON, B.S., ${ }^{4}$ \\ RUI L. REIS, Ph.D., ${ }^{1,2}$ and ANTONIOS G. MIKOS, Ph.D. ${ }^{3}$
}

\begin{abstract}
Tissue engineering strategies aim at controlling the behavior of individual cells to stimulate tissue formation. This control is achieved by mimicking signals that manage natural tissue development or repair. Flow perfusion bioreactors that create culture environments with minimal diffusion constraints and provide cells with mechanical stimulation may closely resemble in vivo conditions for bone formation. Therefore, these culturing systems, in conjunction with an appropriate scaffold and cell type, may provide significant insight towards the development of in vitro tissue engineering models leading to improved strategies for the construction of bone tissue substitutes. The objective of this study was to investigate the in vitro localization of several bone growth factors that are usually associated with bone formation in vivo by culturing rat bone marrow stromal cells seeded onto starch-based biodegradable fiber meshes in a flow perfusion bioreactor. The localization of several bone-related growth factors-namely, transforming growth factor- $\beta 1$, platelet-derived growth factor-A, fibroblast growth factor-2, vascular endothelial growth factor, and bone morphogenetic protein-2-was determined at two different time points in scaffolds cultured under perfusion conditions at two different flow rates using an immunohistochemistry technique. The results show the presence of regions positively stained for all the growth factors considered, except platelet-derived growth factor-A. Furthermore, the images obtained from the positively stained sections suggest an increase in the immunohistochemically stained area at the higher flow rate and culture time. These observations demonstrate that flow perfusion augments the functionality of scaffold/cell constructs grown in vitro as it combines both biological and mechanical factors to enhance cell differentiation and cell organization within the construct. This study also shows that flow perfusion bioreactor culture of marrow stromal cells, combined with the use of appropriate biodegradable fiber meshes, may constitute a useful model to study bone formation and assess bone tissue engineering strategies in vitro.
\end{abstract}

\section{INTRODUCTION}

B ONE TISSUE ENGINEERING APPROACHES based on biodegradable scaffolds seeded with cells and cultured in vitro prior to implantation aim at creating in vitro environments that mimic the biochemical and mechanical signals responsible for natural bone development and repair. Therefore, in order to design successful strategies that en-

\footnotetext{
13 Bs Research Group-Biomaterials, Biodegradables and Biomimetics, University of Minho, Campus de Gualtar, Braga, Portugal.

${ }^{2}$ Department of Polymer Engineering, University of Minho, Campus de Azurém, Guimaraes, Portugal.

${ }^{3}$ Department of Bioengineering, Rice University, Houston, Texas.

${ }^{4}$ Department of Plastic Surgery, The University of Texas M.D. Anderson Cancer Center, Houston, Texas.
} 
able the development of functional bone-like tissue substitutes, it is important to understand the mechanisms of cell growth and differentiation involved in the formation of bone tissue. Although techniques for studying bone formation in vivo have been well developed for many years, adequate in vitro models are not available. This is due, in part, to the complexity of the bone formation process. It is unlikely that osteoblastic cells in culture will express and secrete all of the proteins necessary for the formation of normally mineralized bone in vitro ${ }^{1}$ as it is difficult to capture the complexities of the in vivo environment. ${ }^{2}$ Nevertheless, the available data, most of which are based on observations of normal fetal rat calvarial osteoblasts in prolonged culture, suggest that the process of bone formation depends on the sequential expression and interaction of a number of growth factors. ${ }^{1,3}$

A plethora of growth factors are involved in bone and cartilage formation, and the repair of musculoskeletal tissues. ${ }^{4-8}$ Among the most widely studied bone growth factors are transforming growth factor- $\beta 1$ (TGF- $\beta 1$ ), platelet-derived growth factor (PDGF), bone morphogenetic proteins (BMP), fibroblast growth factors (FGF), and insulin-like growth factors (IGF). ${ }^{4-9}$ However, other growth factors have also been shown to have an effect on bone cells, ${ }^{10}$ including members of the epidermal growth factor family (EGF), transforming growth factor$\alpha$ (TGF- $\alpha$ ) and vascular endothelial growth factor (VEGF). ${ }^{10}$ In fact, the total number of growth factors known to affect proliferation, differentiation, and secretory functions of bone-related cells increases continually as a result of new techniques in protein biochemistry and molecular biology. ${ }^{5}$ Therefore, assessment of the expression of bone growth factors may provide important information on the functionality of bone-like tissue substitutes developed by in vitro bone tissue engineering systems. Additionally, it may provide clues for a better understanding of bone formation mechanisms.

In previous studies, ${ }^{11-13}$ we have used a flow perfusion bioreactor as a culturing system for rat bone marrow stromal cells seeded onto starch-based biodegradable scaffolds in order to evaluate the potential of this tissue engineering approach for the generation of osteoinductive bone tissue replacement constructs. The results show that biodegradable starch-based scaffolds, in conjunction with a fluid flow bioreactor, enable the creation of culture environments with minimal diffusional constraints and provide mechanical stimulation to marrow stromal cells. ${ }^{11-13}$ This approach leads to enhancement of the differentiation of the marrow stromal cells and development of a bone-like extracellular matrix consisting of a carbonated apatite mineral similar to the major mineral component of bone. ${ }^{11,12}$ The design of this flow perfusion bioreactor enhances the distribution of nutrients because it allows the transport of media through the intercon- nected pores of the scaffold. In addition, it offers a convenient way of providing mechanical stimulation to cells by means of fluid shear stress, which is particularly important in bone tissue engineering since bone cells are known to be stimulated by mechanical signals. ${ }^{14,15}$ Furthermore, the magnitude of the shear stresses experienced by the cells can be varied easily by adjusting the flow rate of the media through the system. ${ }^{16}$ Therefore, the characteristics of the flow perfusion bioreactor, in conjunction with scaffolds having suitable properties and porous structures, may facilitate the in vitro development of tissue-like constructs for the regeneration of bone tissue defects.

The present study investigates the localization of several bone growth factors, usually associated with bone formation in vivo, in tissue engineered constructs obtained by in vitro culturing of rat bone marrow stromal cells seeded onto a biodegradable polymer scaffold in a flow perfusion bioreactor at different flow rates and culture periods. This work also describes a novel approach in which an immunohistochemical technique was used to assess the presence of several bone-related growth factors on samples obtained from the in vitro culture of cells seeded onto a biodegradable scaffold using a bioreactor. Specifically, this study was designed to answer the following questions: 1) Is it possible to use immunohistochemical techniques to analyze the presence of bone growth factors on samples cultured in vitro? 2) Are bone growth factors, usually found in vivo, present in cellseeded scaffolds cultured in a flow perfusion bioreactor? 3 ) Is the in vitro tissue engineering approach described suitable as a model for studies on bone formation?

\section{MATERIALS AND METHODS}

\section{Scaffold preparation}

The polymer scaffolds used in this study were based on a blend of corn starch and poly( $\varepsilon$-caprolactone) (SPCL, 30/70 wt\%) obtained by a fiber bonding process consisting of spinning, cutting, and sintering fibers with a diameter of $\sim 180 \mu \mathrm{m}$. The porosity and porous structure of these scaffolds were characterized previously by microcomputed tomography $(\mu \mathrm{CT})$ and scanning electron microscopy (SEM), which showed that the scaffolds exhibited a typical interconnected fiber mesh structure with a porosity of approximately $75 \% .{ }^{13}$

All samples were cut into discs with diameters of $\sim 8$ $\mathrm{mm}$ and heights of 1.5-2 $\mathrm{mm}$ and were subsequently sterilized using ethylene oxide. Prior to cell seeding, the scaffolds were immersed in $30 \mathrm{~mL}$ of serum-free medium in $50 \mathrm{~mL}$ tubes. Air was removed from the pores of the scaffolds by generating vacuum with a $30 \mathrm{~mL}$ syringe 
equipped with an 18 gauge needle. The scaffolds were left in serum-free medium overnight to allow for swelling.

\section{Isolation and expansion of rat bone marrow stromal cells}

Rat bone marrow stromal cells (MSC) were obtained from the femora and tibiae of male Wistar rats, with weights ranging from 125-149 g (Harlan, Indianapolis, IN). The isolation and culturing procedures of the rat bone marrow stromal cells have been described in detail elsewhere. ${ }^{13}$ Briefly, femora and tibiae were removed and washed in medium with an antibiotic concentration 10 times higher than in the complete culture medium used in the remaining experiments. The epiphyses were cut off, and the diaphyses flushed with $5 \mathrm{~mL}$ of complete medium (see below). The bone marrow obtained from all the rats was pooled and plated into $75 \mathrm{~cm}^{2}$ flasks. The cells were cultured at $37^{\circ} \mathrm{C}$ in a humidified atmosphere with $5 \% \mathrm{CO}_{2}$. The complete culture medium for the experiment consisted of minimum essential medium $(\alpha$ MEM Eagle, Sigma, St. Louis, MO) supplemented with $10 \%$ fetal calf serum (FCS, Gemini, Woodlands, CA), 50 $\mu \mathrm{g} / \mathrm{mL}$ ascorbic acid, $50 \mu \mathrm{g} / \mathrm{mL}$ gentamycin, $100 \mu \mathrm{g} / \mathrm{mL}$ ampicillin, $0.3 \mu \mathrm{g} / \mathrm{mL}$ fungizone, $10 \mathrm{mM} \beta$-glycerophosphate, and $10^{-8} \mathrm{M}$ dexamethasone (Sigma). The culture medium was refreshed after $24 \mathrm{~h}$ and thereafter every 2 days until day 6 .

\section{Cell seeding}

At near confluence, after 6 days of primary culture, the adherent cells were enzymatically released using trypsin/ EDTA $(0.25 \%$ w/v trypsin $/ 0.02 \%$ EDTA, Sigma), concentrated by centrifugation at $400 \mathrm{~g}$ for $5 \mathrm{~min}$ and resuspended in complete medium. Subsequently, the scaffolds were inserted into flow system cassettes that were placed in 6 well plates. Each scaffold was then seeded with $300 \mu \mathrm{L}$ of cell suspension containing $5 \times 10^{5}$ cells and incubated for $2 \mathrm{~h}$. Then, $10 \mathrm{~mL}$ of media was added to each well, and the seeded scaffolds were incubated overnight to allow further cell attachment. The following day seeded scaffolds were placed into the flow perfusion bioreactor and cultured in complete media for 10 and 16 days (6 scaffolds per culture time). Seeded scaffolds cultured under static conditions ( 6 well plates) were used as controls.

\section{Cell culture}

The flow perfusion bioreactor used in this study is described in detail elsewhere. ${ }^{16}$ Briefly, this bioreactor consists of 6 flow chambers, each containing a cassette in which the scaffold is press-fitted. Gas-permeable silicon tubing connects each flow chamber with a peristaltic pump and a media reservoir. Each chamber has an independent pumping circuit, but all pumps draw media from a common reservoir. For these experiments, two bioreactor systems were used simultaneously at two different flow rates, namely, $1 \mathrm{~mL} / \mathrm{min}$ and $0.3 \mathrm{~mL} / \mathrm{min}$. The total volume of media continuously flowing in the system was $210 \mathrm{~mL}$, and the entire volume was changed every 3 days. The flow perfusion bioreactor was maintained in an environment of $37^{\circ} \mathrm{C}$ with $5 \% \mathrm{CO}_{2}$.

\section{Immunohistochemical analysis}

Sample processing. At the end of each culturing period, the cell/mesh constructs were removed from the bioreactors, rinsed with a phosphate buffer saline solution (PBS, $0.01 \mathrm{M}, \mathrm{pH} 7.4$ ) and fixed in a $10 \%$ formalin solution (Sigma). The constructs were then rinsed with PBS, cut in half, embedded in optimal freezing temperature compound (OCT, Tissue-Tek, Torrance, CA) and frozen on dry ice. Serial sections (10 $\mu \mathrm{m}$ in thickness) were prepared and stored at $-80^{\circ} \mathrm{C}$ until staining. The sections were marked according to their distance from the surface of the scaffold in order to analyze differences within a given scaffold. Sections obtained from all scaffolds were analyzed for the presence of each of the growth factors being studied.

Primary antibodies. For this study, the following antibodies were selected: anti-transforming growth factor- $\beta 1$ (anti-TGF- $\beta 1$, goat polyclonal antibody, sc-146-G), antiplatelet-derived growth factor-A (anti-PDGF-A, mouse monoclonal antibody, sc-9974), anti-fibroblast growth factor-2 (anti-FGF-2, goat polyclonal antibody, sc-79-G), anti-vascular endothelial growth factor (anti-VEGF, mouse monoclonal antibody, sc-7269), and anti-bone morphogenetic protein-2 (anti-BMP-2, goat polyclonal antibody, sc-6895). All antibodies were purchased from Santa Cruz Biotechnology (Santa Cruz, CA) and used at a concentration of $2 \mu \mathrm{g} / \mathrm{mL}$ of $0.1 \mathrm{M}$ PBS. The diluted antibody solutions were used on the same day they were prepared. The mouse monoclonal antibodies were used in conjunction with an anti-mouse avidin-biotin complex $\mathrm{ABC}$ kit, and the goat polyclonal antibodies were used in conjunction with an anti-goat $\mathrm{ABC}$ kit (both Vectastain Elite ABC kit, Vector Laboratories, Burlingame, CA).

Immunostaining procedure. The sections were immunostained using the avidin-biotin immunoperoxidase staining technique, which is based on the ability of eggwhite glycoprotein avidin to nonimmunologically bind four molecules of the vitamin biotin. ${ }^{17}$ This technique uses three main reagents: 1) a primary antibody specific for the antigen to be localized; 2) anti-mouse/anti-goat polyclonal antibody (secondary), which is covalently linked to a molecule of biotin; and 3) a complex of per- 
Table 1. Sequence and Length of Incubation Periods Involved in Immunohistochemical Staining Procedure

\begin{tabular}{llcc}
\hline Step & \multicolumn{1}{c}{ Reagent } & Incubation & Rinses $(2 \times)$ \\
\hline 1 & $95 \%$ Ethanol & $3 \mathrm{~min}$ & Distilled water \\
2 & $\mathrm{H}_{2} \mathrm{O}_{2} / \mathrm{CH}_{3} \mathrm{OH}$ & $1 \mathrm{~h}$ & Wash buffer* \\
3 & Normal serum & $1 \mathrm{~h}$ & Wash buffer \\
4 & Primary antibody & $2 \mathrm{~h}$ & Wash buffer \\
5 & Secondary antibody & $1 \mathrm{~h}$ & Wash buffer \\
6 & ABC reagent & $1 \mathrm{~h}$ & Distilled water \\
7 & DAB reagent & $10 \mathrm{~min}$ & \\
8 & Hematoxylin & $8 \mathrm{~min}$ & \\
9 & Tap water & $1 \mathrm{~min}(2 \times)$ & \\
10 & Acid alcohol & $3 \mathrm{~min}$ & Distilled water \\
11 & $95 \%$ Ethanol & $3 \mathrm{~min}(2 \times)$ & \\
12 & $100 \%$ Ethanol & 3 min $(2 \times)$ & \\
\hline
\end{tabular}

*Wash buffer: PBS with surfactant (OptiMax).

oxidase conjugated with biotin and avidin. The free sites on the avidin molecule allow binding to the biotin present on the second antibody. The peroxidase enzyme is identified with an appropriate chromogen, allowing visualization of the original antigen. ${ }^{17}$

The experimental staining procedure was based on previously established protocols ${ }^{18}$ and can be briefly de- scribed as follows: the sections were first incubated in a hydrogen peroxide solution to block against endogenous peroxidase activity and then incubated with normal serum (provided in the ABC kit referenced above) to block against random secondary antibody binding. The sections were then incubated with primary antibody for the antigen of interest, followed by the avidin-biotin secondary a)

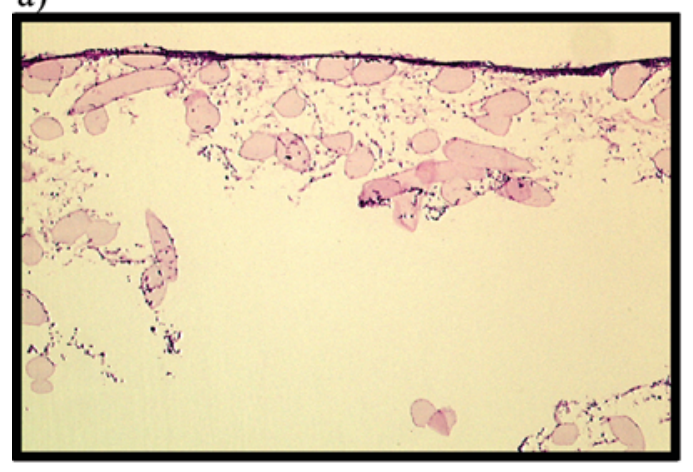

c)

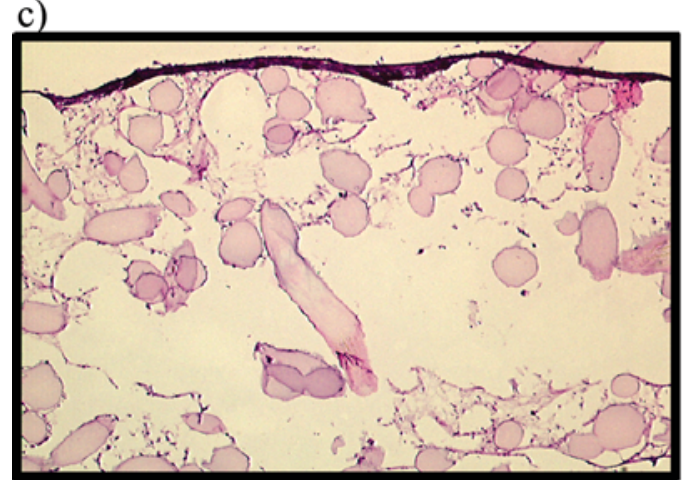

b)

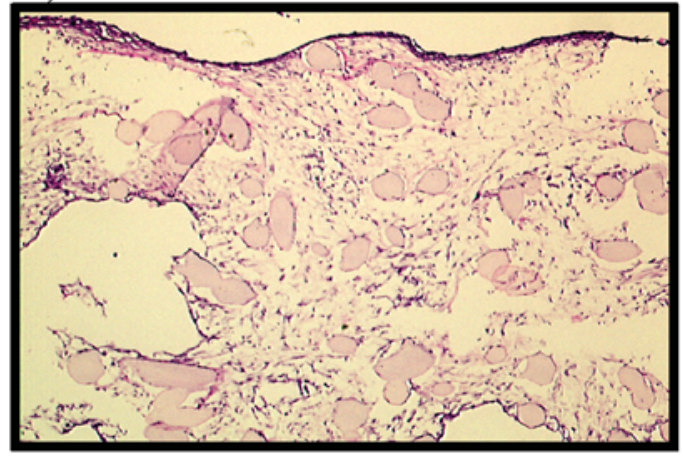

d)

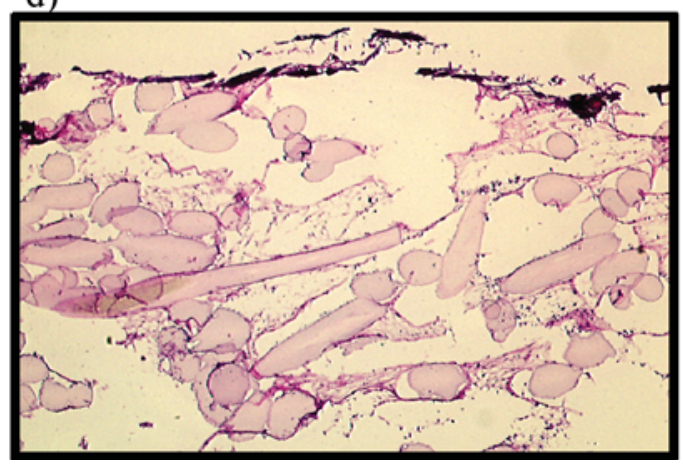

FIG. 1. Light microscopy images $(4 \times$ original magnification $)$ of SPCL scaffold/cell constructs cultured under flow perfusion for 10 and 16 days, at two different flow rates and stained with hematoxilin and eosin. (A) Construct cultured for 10 days at a flow rate of $0.3 \mathrm{~mL} / \mathrm{min}$. (B) Construct cultured for 10 days at a flow rate of $1 \mathrm{~mL} / \mathrm{min}$. (C) Construct cultured for 16 days at a flow rate of $0.3 \mathrm{~mL} / \mathrm{min}$. (D) Construct cultured for 16 days at a flow rate of $1 \mathrm{~mL} / \mathrm{min}$. (Images available in color in online version.) 
antibody system and the developing reagent (3,3'-diaminobenzidin, DAB, Vector Laboratories). As a last step, the sections were counterstained with hematoxylin and mounted. The negative staining controls consisted of sections incubated with $0.01 \mathrm{M}$ PBS instead of the primary antibody. A group of samples received conventional hematoxylin and eosin staining. The whole procedure was performed at room temperature. Table 1 summarizes the sequence and length of the incubation periods involved in this staining procedure.

Image acquisition. All the stained sections were observed with an Eclipse E600 light microscope (Nikon, Melville, NY) equipped with a CCD camera (Sony DXC950P, New York, NY). For each stained section, three digital images were taken, corresponding to the two ends and center of the sample (magnification $\times 4$ ).

\section{RESULTS}

Histological analysis of SPCL scaffold/cell constructs stained for hematoxilin and eosin showed the presence of cells and matrix distributed throughout the interior of the three-dimensional starch-based scaffolds and also the formation of a thick surface layer of cells (Fig. 1). Furthermore, these images suggest an increase in the number of cells and amount of matrix at the higher flow rate, in agreement with previous studies ${ }^{15,19}$ that demonstrated that flow perfusion culture enhances the osteoblastic differentiation of marrow stromal cells (MSC) and improves their distribution in the scaffolds in a dose-dependent manner by improving nutrient delivery to the interior of the scaffolds and stimulating the seeded cells by exposing them to fluid shear forces. Additionally, an increase in the number of cells and amount of matrix with increasing culture time was observed, as expected. As a comparison, Figure 2 shows images obtained from the control sections, which were incubated with PBS instead of the antibody. No positive staining was detected in these sections.

\section{Vascular endothelial growth factor (VEGF)}

In Figure 3, typical light microscopy images show immunohistochemical staining of sample sections cultured in the flow perfusion bioreactor for 10 and 16 days un-

b)
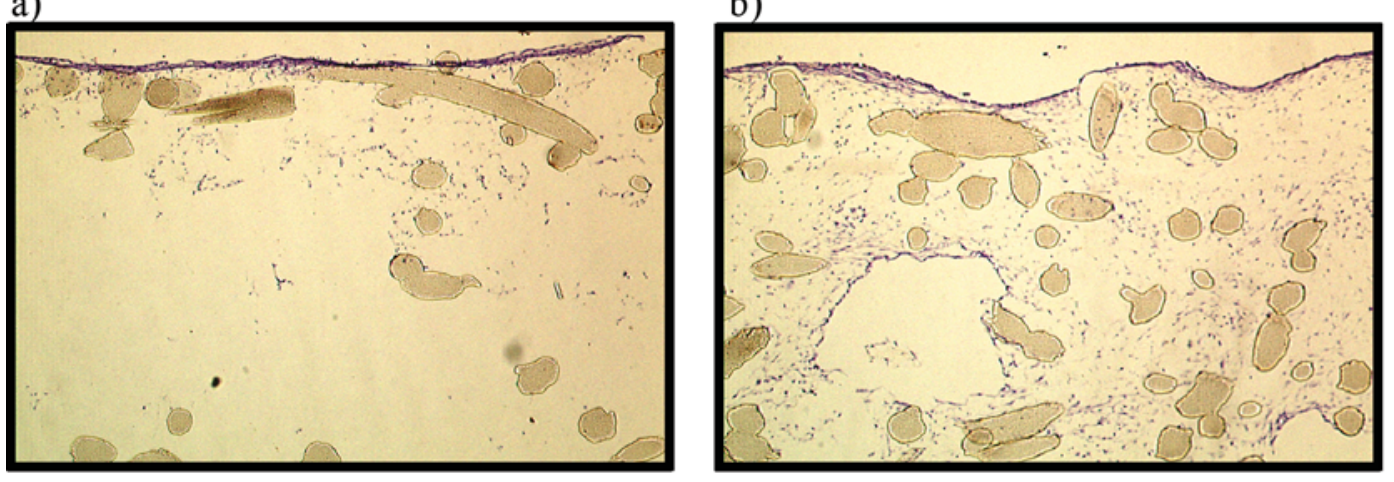

c)

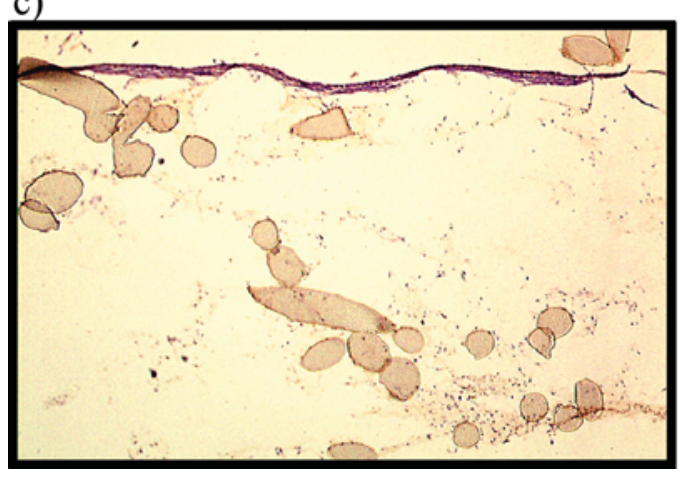

d)

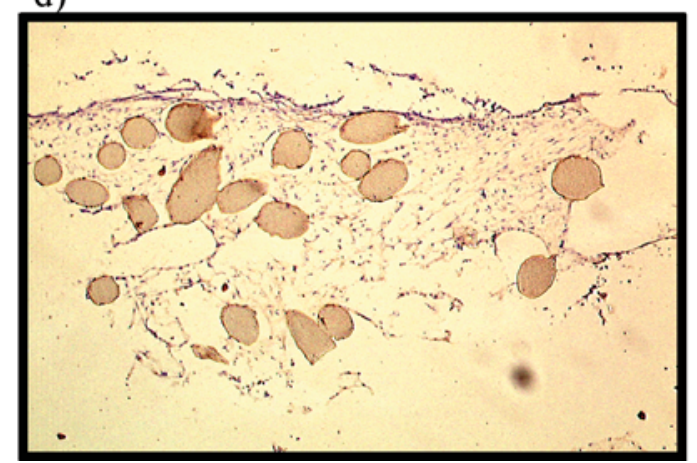

FIG. 2. Light microscopy images $(4 \times$ original magnification) of SPCL scaffold/cell constructs cultured under flow perfusion for 10 and 16 days, at two different flow rates and incubated with PBS instead of a primary antibody (controls). (A) Construct cultured for 10 days at a flow rate of $0.3 \mathrm{~mL} / \mathrm{min}$. (B) Construct cultured for 10 days at a flow rate of $1 \mathrm{~mL} /$ min. (C) Construct cultured for 16 days at a flow rate of $0.3 \mathrm{~mL} / \mathrm{min}$. (D) Construct cultured for 16 days at a flow rate of 1 $\mathrm{mL} / \mathrm{min}$. (Images available in color in online version.) 
a)

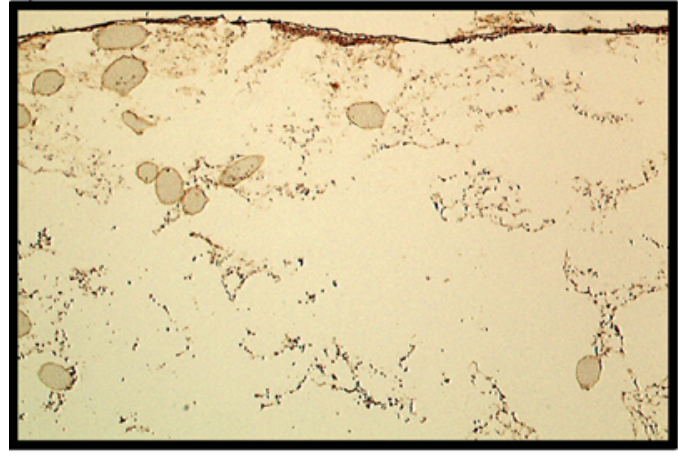

c)

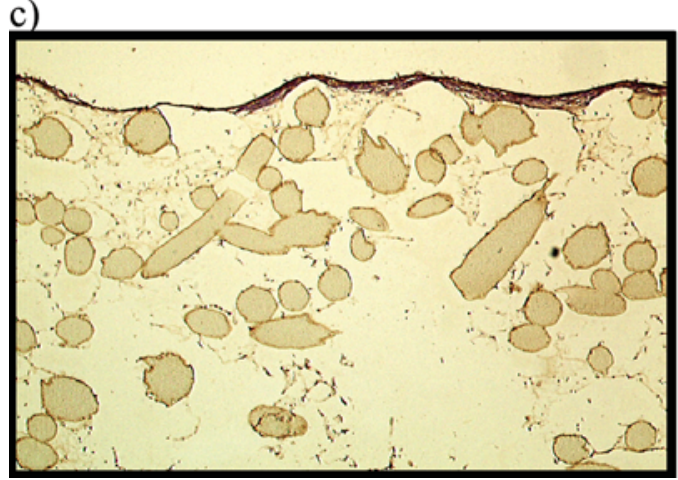

b)

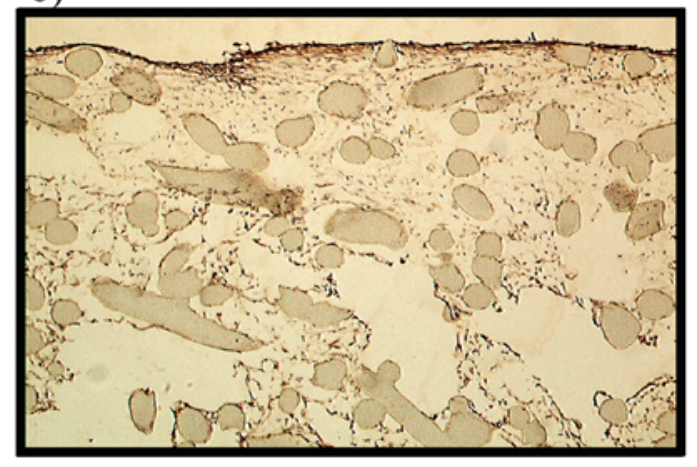

d)

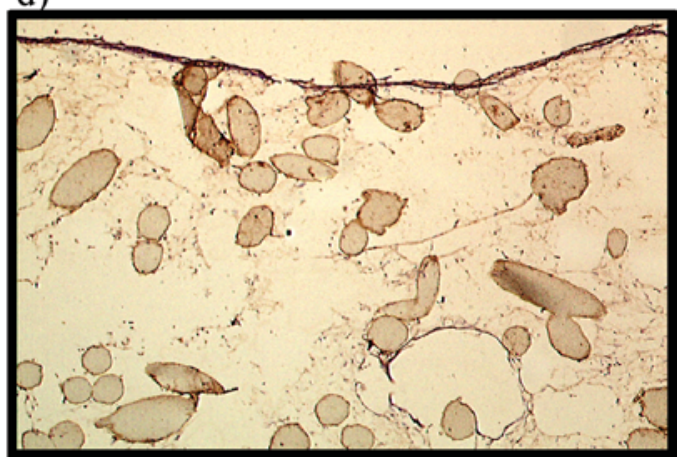

FIG. 3. Light microscopy images $(4 \times$ original magnification) of SPCL scaffold/cell constructs cultured under flow perfusion for 10 and 16 days, at two different flow rates and immunostained for VEGF. (A) Construct cultured for 10 days at a flow rate of $0.3 \mathrm{~mL} / \mathrm{min}$. (B) Construct cultured for 10 days at a flow rate of $1 \mathrm{~mL} / \mathrm{min}$. (C) Construct cultured for 16 days at a flow rate of $0.3 \mathrm{~mL} / \mathrm{min}$. (D) Construct cultured for 16 days at a flow rate of $1 \mathrm{~mL} / \mathrm{min}$. (Images available in color in online version.)

der two different flow rates. In addition to showing the presence of stained areas in sections analyzed for VEGF, these images suggest an increase in the immunohistochemically stained area at the higher flow rate. This effect might be related to enhanced differentiation due to increased mechanical stimulation of the cells. It has been previously demonstrated that the increase of fluid flow in this flow perfusion bioreactor leads to enhanced differentiation and mineralization of marrow stromal cells cultured in three-dimensional starch-based scaffolds. ${ }^{13}$ In addition, there was an increase in growth factor expression after 16 days in culture relative to 10 days, which is probably associated with increased cell and matrix content within the constructs.

\section{Platelet-derived growth factor-A}

Contrary to what was observed in the sections stained for VEGF, the sections stained for PDGF-A looked similar to the control samples, which were incubated with PBS instead of the antibody, (Fig. 4). There was no positive staining for this growth factor, demonstrating that PDGF-A is not expressed by MSCs cultured under the described conditions. However, using the presently avail- able data, it is not possible to determine whether this growth factor is present in this system at earlier or later stages of culture.

\section{Transforming growth factor- $\beta 1$}

Typical light microscopy images of sections obtained from samples cultured in the flow perfusion bioreactor for 10 and 16 days under two different flow rates and immunohistochemically stained for TGF- $\beta 1$ are seen in Figure 5. In the sections obtained from samples cultured for 10 days at the lower flow rate, there are only some regions that are positively stained. In contrast, for all remaining samples, there is widespread localization of this growth factor. This indicates that expression of TGF- $\beta 1$ can be related to a specific period of cell development, which is enhanced by increasing the stimulation due to higher flow rate used in the perfusion bioreactor.

\section{Fibroblast growth factor}

Images depicting sections obtained from scaffold/cell constructs cultured under previously described conditions and stained for FGF-2 are shown in Figure 6. They dem- 

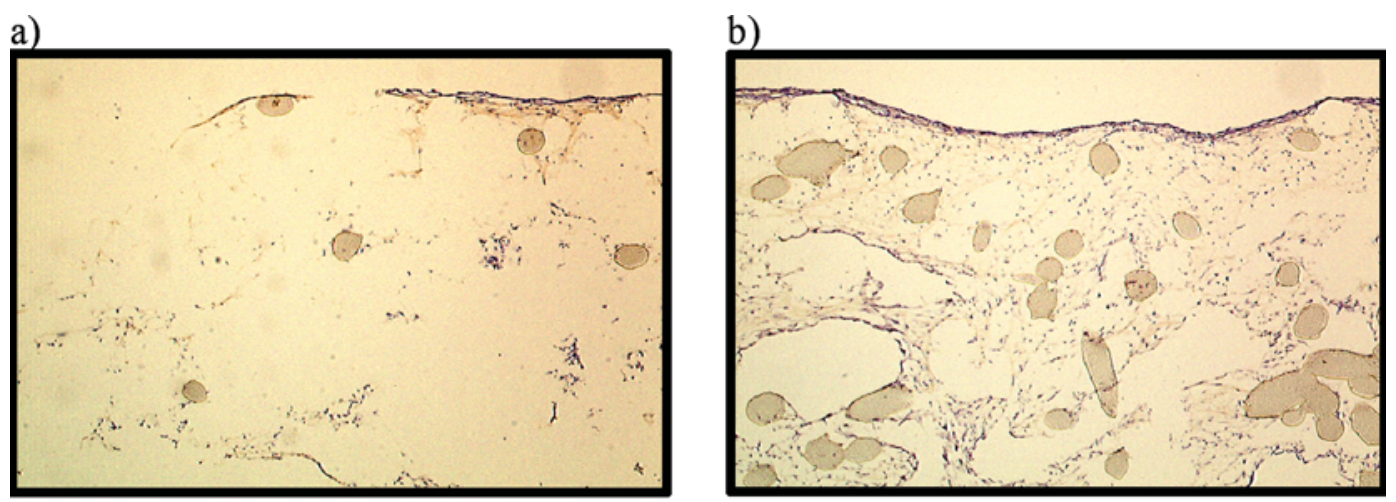

c)

d)
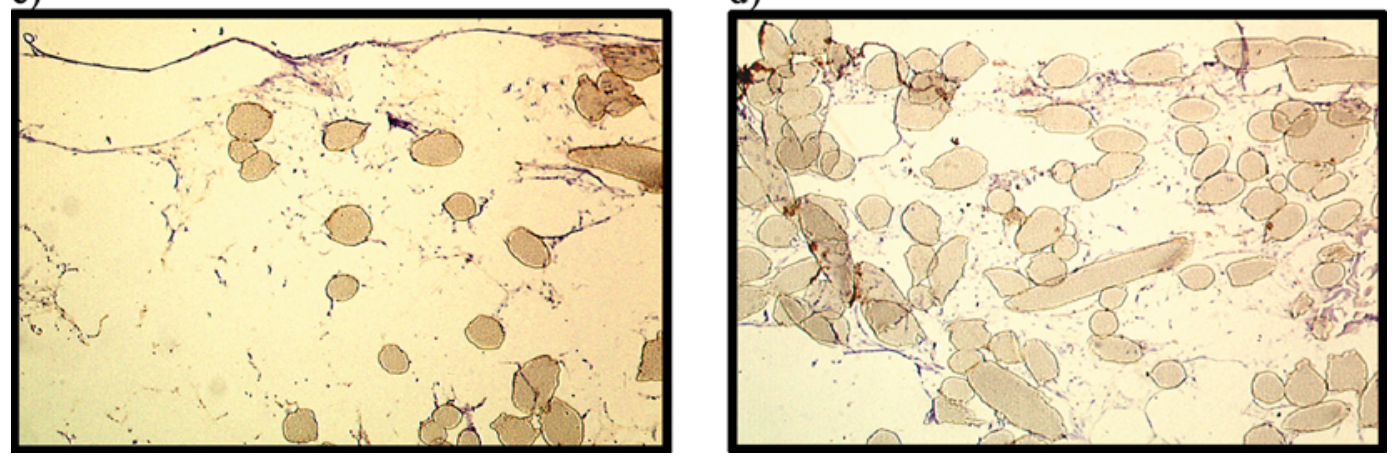

FIG. 4. Light microscopy images $(4 \times$ original magnification) of SPCL scaffold/cell constructs cultured under flow perfusion for 10 and 16 days, at two different flow rates and immunostained for PDGF-A. (A) Construct cultured for 10 days at a flow rate of $0.3 \mathrm{~mL} / \mathrm{min}$. (B) Construct cultured for 10 days at a flow rate of $1 \mathrm{~mL} / \mathrm{min}$. (C) Construct cultured for 16 days at a flow rate of $0.3 \mathrm{~mL} / \mathrm{min}$. (D) Construct cultured for 16 days at a flow rate of $1 \mathrm{~mL} / \mathrm{min}$. (Images available in color in online version.)

onstrate the presence of several regions, corresponding to cells and matrix formed within the construct, which are positively stained for this growth factor. Once again, a larger stained area is visible in the samples cultured under the higher perfusion rate, demonstrating the capability of influencing cell behavior by the selection of different levels of mechanical stimulation with the flow perfusion bioreactor.

\section{Bone morphogenetic protein-2}

Figure 7 shows the light microscopy images of sections obtained from constructs cultured for 10 and 16 days in the flow perfusion bioreactor, using flow rates of 0.3 and $1 \mathrm{~mL} / \mathrm{min}$ and immunohistochemically stained for BMP-2. In these images, it is possible to identify areas positively stained for BMP-2, mostly localized in the cells and their surrounding matrix. The sections stained for BMP-2 that correspond to samples cultured at the higher flow rate exhibit increased levels of expression of this growth factor, demonstrated by the presence of a higher number of spots per area positively stained. This was observed in all the samples positively analyzed for the growth factors previously described, indicating that it is possible to modulate cell development by tailoring the culturing parameters. Specifically, this result suggests that higher flow rates enhance the development of rat bone marrow cells, and therefore mechanical stimulation induced by this culturing parameter to the cells can be adjusted to lead to the development of tissue engineering constructs in useful (i.e., shorter) culturing times and/or to obtain bone tissue-like constructs with enhanced functionality.

\section{DISCUSSION}

The light microscopy images obtained from three different regions of each of the six samples studied per group (culturing period-flow rate) that were immunohistochemically analyzed consistently showed the presence of regions positively stained for all the growth factors examined (namely, BMP-2, FGF-2, VEGF, and TGF- $\beta 1$ ), except for PDGF-A. These images suggest an increase in the immunohistochemically stained area with increasing flow rate, which was observed for all positively stained sections, as well as a trend of enhanced growth factor expression over culturing time. The images taken from the two ends of a sample revealed no differences in staining 
a)

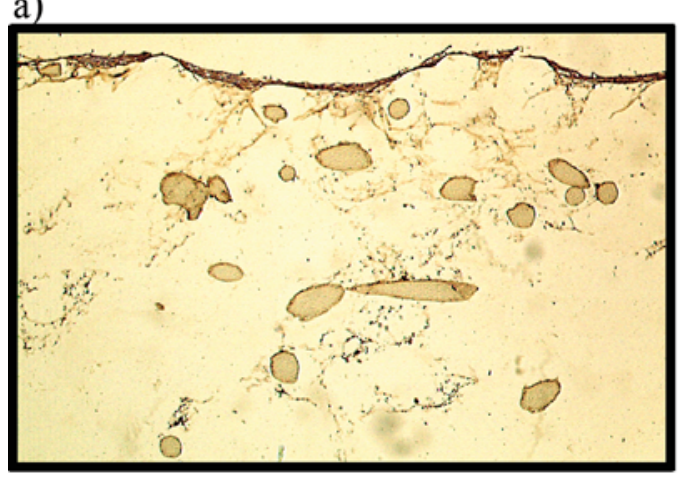

c)

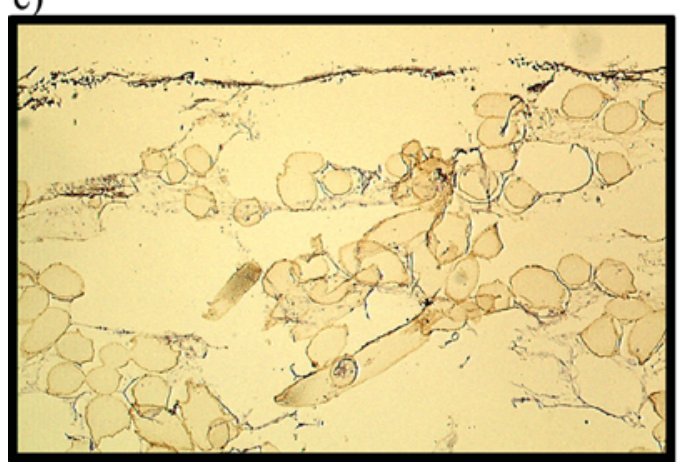

b)

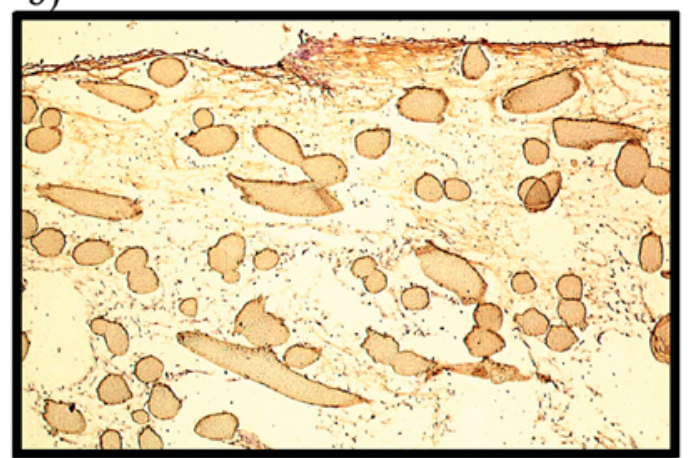

d)

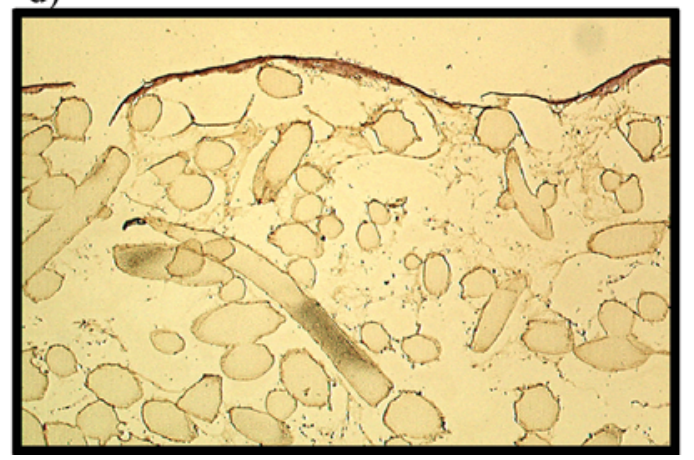

FIG. 5. Light microscopy images $(4 \times$ original magnification) of SPCL scaffold/cell constructs cultured under flow perfusion for 10 and 16 days, at two different flow rates and immunostained for TGF- $\beta 1$. (A) Construct cultured for 10 days at a flow rate of $0.3 \mathrm{~mL} / \mathrm{min}$. (B) Construct cultured for 10 days at a flow rate of $1 \mathrm{~mL} / \mathrm{min}$; (C) Construct cultured for 16 days at a flow rate of $0.3 \mathrm{~mL} / \mathrm{min}$. (D) Construct cultured for 16 days at a flow rate of $1 \mathrm{~mL} / \mathrm{min}$. (Images available in color in online version.)

compared with that of the center (data not shown); the image from the center of a sample is presented here. The differences between sections of the same sample or sections of samples obtained using identical culture conditions were also not significant.

The results provide evidence that growth factors can be delivered into a scaffold via cotransplantation of cells that can naturally produce them when cultured in stimulating conditions and can accelerate the healing and/or neotissue development upon implantation of the construct. For instance, the presence of VEGF in these constructs, a polypeptide growth factor that is known to specifically promote the proliferation of vascular endothelial cells, ${ }^{10}$ may enhance vascular tissue formation upon their implantation, increasing the viability of the transplanted cells and tissue within the scaffold. In fact, the induction of rapid vascular ingrowth has been a major limitation in bone tissue engineering, ${ }^{20,21}$ particularly when the aim is to restore a large tissue defect. This is because when a tissue engineered construct is implanted the transplanted cells, as well as the native host cells that migrate into the scaffold, depend upon the transport of nutrients and waste products between the cells and the host tissue for survival; as the transport in this first stage is carried out exclusively by diffusion, cells that are more than several hundred microns from blood vessels in the surrounding tissue frequently either fail to engraft or die rapidly due to oxygen deprivation. ${ }^{22}$ Therefore, the presence of VEGF in the constructs might be extremely beneficial for the development of new bone tissue as it is likely to enhance their vascularization upon implantation and thus provide adequate delivery of nutrients and oxygen into the developing tissue.

Like VEGF, FGFs are also angiogenic factors that are important for neovascularization during bone healing. ${ }^{5}$ FGFs have primarily a proliferative effect on osteoblasts and a lesser effect on protein synthesis. Consequently, they probably enhance bone formation by increasing the number of cells capable of synthesizing bone matrix.$^{5,23,24}$ FGF- 2 can also stimulate the TGF- $\beta$ synthesis by osteoblasts and may therefore exert some stimulatory effects through other growth factors. ${ }^{5,23}$ Therefore, the expression of these growth factors in the scaffold/cell constructs cultured under flow perfusion can have a positive impact on the functionality of these tissue engineered substitutes upon implantation. 

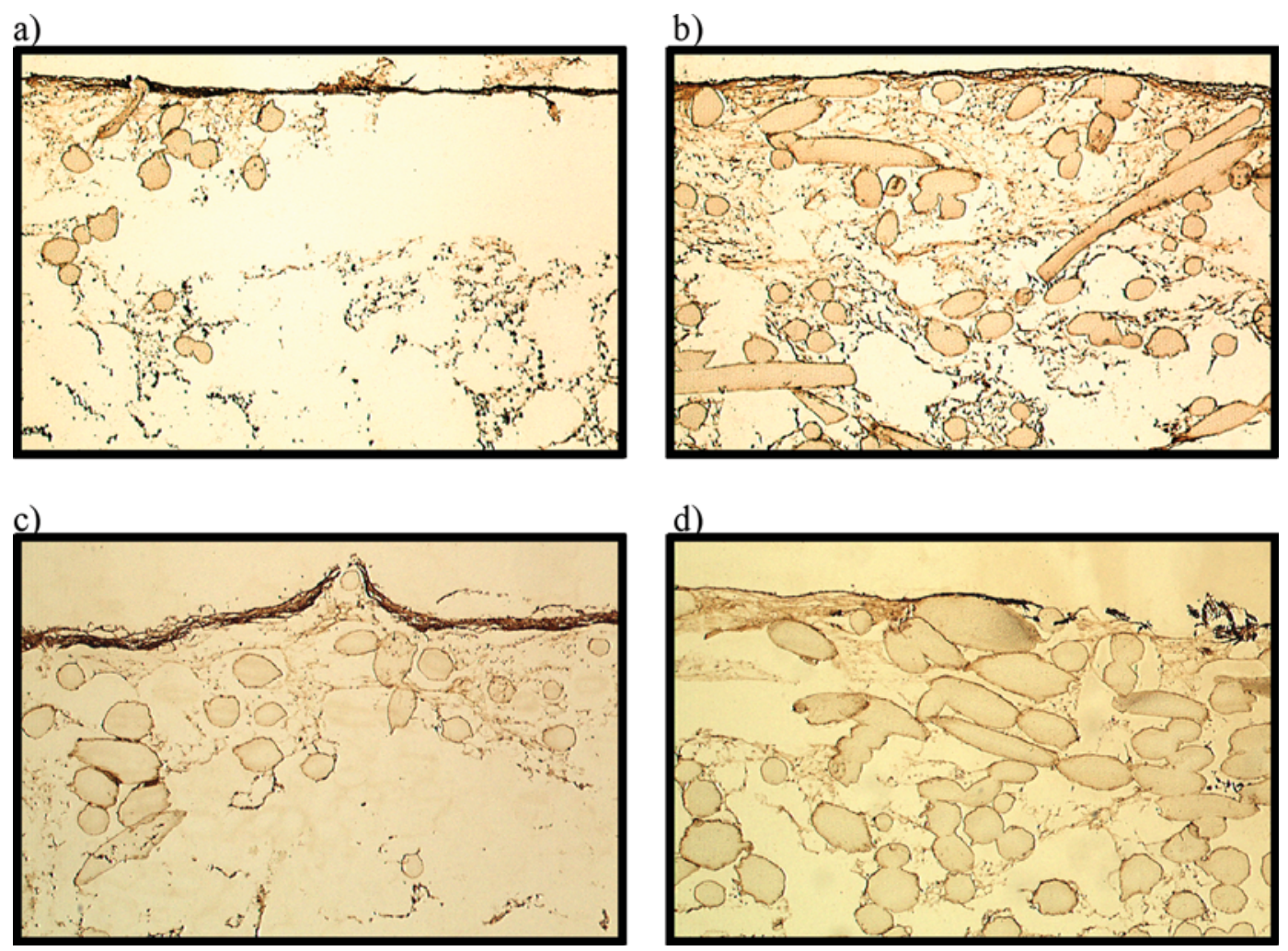

FIG. 6. Light microscopy images $(4 \times$ original magnification) of SPCL scaffold/cell constructs cultured under flow perfusion for 10 and 16 days, at two different flow rates and immunostained for FGF-2. (A) Construct cultured for 10 days at a flow rate of $0.3 \mathrm{~mL} / \mathrm{min}$. (B) Construct cultured for 10 days at a flow rate of $1 \mathrm{~mL} / \mathrm{min}$. (C) Construct cultured for 16 days at a flow rate of $0.3 \mathrm{~mL} / \mathrm{min}$. (D) Construct cultured for 16 days at a flow rate of $1 \mathrm{~mL} / \mathrm{min}$. (Images available in color in online version.)

The presence of the platelet-derived growth factors (PDGF), which was not observed in this study, could have important effects in the early stages of fracture healing, as it can be released during platelet aggregation. ${ }^{5,6}$ In addition to its effect on bone formation (PDGF stimulates DNA and protein synthesis), PDGF has been shown to stimulate bone resorption, appearing to have a complex effect on bone remodeling. ${ }^{6}$ However, as previously discussed, it is not possible to conclude if this growth factor is present in the described system at earlier or later stages of culture, nor is it possible to predict if the absence of PDGF in the transplanted construct would somehow compromise the adaptation of the implanted construct.

TGF- $\beta 1$, by itself or in conjunction with other growth regulators, has a major function in bone formation ${ }^{6,25,26}$ as it influences a broad range of cellular activities, including growth, proliferation, differentiation, and extracellular matrix synthesis. It is probably the most potent multifunctional regulator of bone cell metabolism., ${ }^{5,6}$ Consequently, its presence on a bone tissue engineering construct would certainly have a positive effect on the functionality and adaptation of the implant.
Bone morphogenetic proteins (BMPs) belong to the same family as TGF- $\beta 1$, the TGF- $\beta$ superfamily, and are known to induce the differentiation of undifferentiated mesenchymal cells into chondrogenic and osteogenic cells and promote their differentiation. ${ }^{5,7}$ In vivo this action may result in bone generation and thus fracture repair by the newly formed bone. ${ }^{27}$ At the cellular level, undifferentiated mesenchymal cells proliferate from the periosteum, bone marrow, and muscle surrounding the fracture and begin to migrate. As a result, new bone is produced in conjunction with their differentiation into chondrogenic and osteogenic cells. In fact, it has been demonstrated that certain BMPs (BMP-2 and/or BMP-4) are present at the initial stage of this fracture healing process and seem to play an important role in several events of the bone formation cascade that leads to bone repair. ${ }^{1}$

Due to its capability of eliciting new bone formation, BMPs have been widely used in bone tissue engineering strategies ${ }^{27,28}$ using a carrier device for delivery at the implantation site. Although the efficacy of this approach in enhancing new bone formation has been shown both orthotopically and heterotopically in several different ex- 
a)

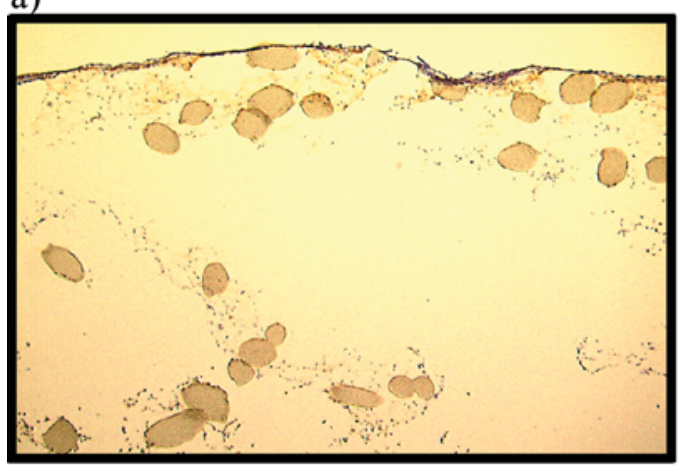

c)

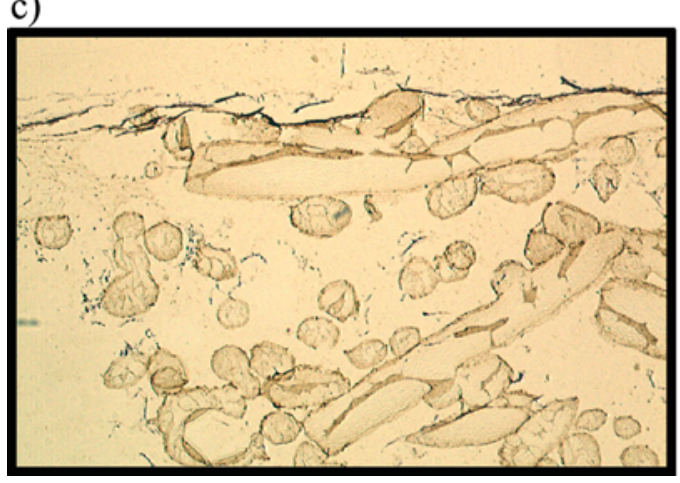

b)

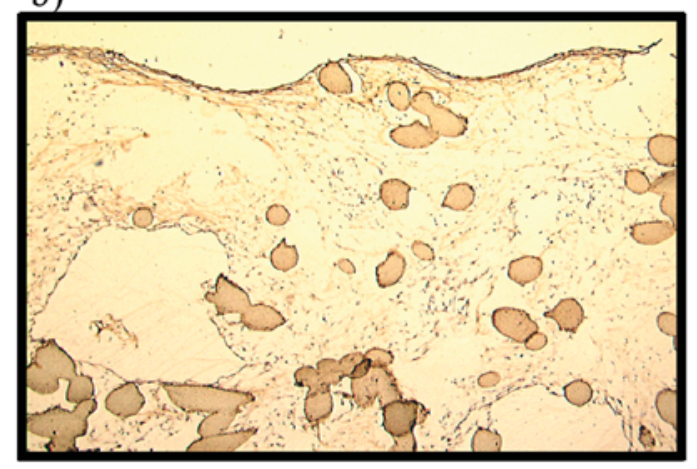

d)

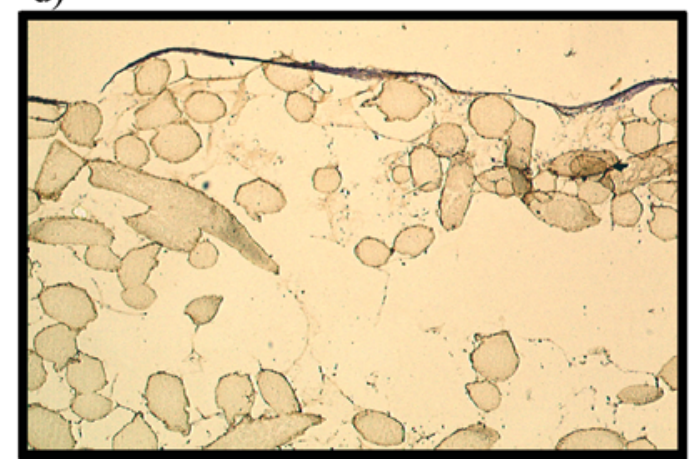

FIG. 7. Light microscopy images $(4 \times$ original magnification) of SPCL scaffold/cell constructs cultured under flow perfusion for 10 and 16 days, at two different flow rates and immunostained for BMP-2. (A) Construct cultured for 10 days at a flow rate of $0.3 \mathrm{~mL} / \mathrm{min}$. (B) Construct cultured for 10 days at a flow rate of $1 \mathrm{~mL} / \mathrm{min}$. (C) Construct cultured for 16 days at a flow rate of $0.3 \mathrm{~mL} / \mathrm{min}$. (D) Construct cultured for 16 days at a flow rate of $1 \mathrm{~mL} / \mathrm{min}$. (Images available in color in online version.)

perimental animal models, ${ }^{27-32}$ the inability to find an ideal delivery system has limited the use of this approach. $27,29,32$

The images taken in this in vitro study may not be compared with those obtained from samples from in vivo studies. ${ }^{18}$ In vivo there is formation of new tissue within a scaffold while in vitro the tissue formation may not be continuous or sufficient to produce stable sections for immunohistochemical analysis. The large number of incubations and washings involved in this analysis may also compromise the final appearance of a section. Nevertheless, this study demonstrates that immunohistochemical analysis can be used to characterize the quality of extracellular matrix generated in vitro using a flow perfusion bioreactor.

This study shows that osteoprogenitor cells seeded in a starch-based biodegradable matrix and stimulated by flow perfusion culturing may be able to deliver growth factors, including BMP-2 after implantation, providing an osteoinductive scaffold for bone regeneration in critical size defects. In this sense, flow perfusion augments the functionality of scaffold/cell constructs grown in vitro as it combines both biological and mechanical factors to enhance cell differentiation and cell organization within the construct.

The results suggest that flow perfusion bioreactor culture of marrow stromal cells combined with biodegradable starch-based fiber meshes may constitute a useful model for in vitro research on the biological mechanisms associated with bone formation and regeneration. The true biological environment of a bone cell is derived from a dynamic interaction between responsively active cells experiencing mechanical forces and a continuously changing three-dimensional matrix architecture, which can be simulated to a limited extent, in this type of bioreactor. Moreover, the data show that starch-based fiber meshes support the expression of the different growth factors by rat bone marrow stromal cells cultured within these scaffolds, providing further evidence of their suitability for bone tissue engineering applications.

\section{ACKNOWLEDGMENTS}

M.E. Gomes acknowledges support from the Portuguese Foundation for Science and Technology (FCT; SFRH/ 
BD/4704/2001). The authors thank Dr. Francesco DegliInnocenti (Novamont, Italy) for supplying the starch-based polymers. This work was funded by a grant from the National Institutes of Health (R01-AR42639) (AGM) and FCT through the POCTI and FEDER programs.

\section{REFERENCES}

1. Mundy, G.R., Boyce, B., Hughes, D., Wright, K., Bonewald, L., Dallas, S., Harris, S., Ghosh-Choudhury, N., Chen, D., Dunstan, C., Izbicka, E., and Yoneda, T. The effects of cytokines and growth factors on osteoblastic cells. Bone 17, 71S, 1995.

2. Davies, J.E. In vitro modeling of the bone/implant interface. Anat. Rec. 245, 426, 1996.

3. Goldstein, S.A., Patil, P.V., and Moalli, M.R. Perspectives on tissue engineering of bone. Clin. Orthop. Rel. Res. S419, 1999.

4. Lieberman, J.R., Daluiski, A., and Einhorn, T.A. The role of growth factors in the repair of bone. Biology and clinical applications. J. Bone Joint Surg. Am. 84, 1032, 2002.

5. Lind, M. Growth factors: possible new clinical tools. Acta Orthop. Scand. 67, 407, 1996.

6. Canalis, E., McCarthy, T., and Centrella, M. Growth factors and the regulation of bone remodeling. J. Clin. Invest. 81, 277, 1988.

7. Urist, M.R., DeLange, R.J., and Finerman, G.A. Bone cell differentiation and growth factors. Science 220, 680, 1983.

8. Wright, V.J., Peng, H., and Huard, J. Muscle-based gene therapy and tissue engineering for the musculoskeletal system. Drug Discov. Today 6, 728, 2001.

9. Harada, S., and Rodan, G.A. Control of osteoblast function and regulation of bone mass. Nature 423, 349-55. 2003.

10. Croucher, P., and Russell, R. Growth factors. In: Seibel, M., Robins, S., and Bilezikian, J., eds., Dynamics of Bone and Cartilage Metabolism. New York: Academic Press, 1999, pp. 83-95.

11. Gomes, M.E., Holtorf, H.L., Reis, R.L., and Mikos, A.G. Influence of the porosity of starch-based fiber mesh scaffolds on the proliferation and osteogenic differentiation of bone marrow stromal cells cultured in a flow perfusion bioreactor. Tissue Eng., in press.

12. Gomes, M.E., Holtorf, H.L., Reis, R.L., and Mikos, A.G. Influence of the porosity of starch-based fiber meshes on the proliferation and osteogenic differentiation of marrow stromal cells cultured under flow perfusion. Paper presented at the Seventh World Biomaterials Conference. Sydney, Australia, 2004.

13. Gomes, M.E., Sikavitsas, V.I., Behravesh, E., Reis, R.L., and Mikos, A.G. Effect of flow perfusion on the osteogenic differentiation of bone marrow stromal cells cultured on starch-based three-dimensional scaffolds. J. Biomed. Mater. Res. 67A, 87, 2003.

14. Sikavitsas, V.I., Temenoff, J.S., and Mikos, A.G. Biomaterials and bone mechanotransduction. Biomaterials 22, 2581, 2001.

15. Sikavitsas, V.I., Bancroft, G.N., Holtorf, H.L., Jansen, J.A., and Mikos, A.G. Mineralized matrix deposition by marrow stromal osteoblasts in 3D perfusion culture increases with increasing fluid shear forces. Proc. Natl. Acad. Sci. USA 100, 14683, 2003.

16. Bancroft, G.N., Sikavitsas, V.I., and Mikos, A.G. Design of a flow perfusion bioreactor system for bone tissue-engineering applications. Tissue Eng. 9, 549, 2003.

17. Vince, D.G., Hunt, J.A., and Williams, D.F. Quantitative assessment of the tissue response to implanted biomaterials. Biomaterials 12, 731, 1991.

18. Fisher, J.P., Lalani, Z., Bossano, C.M., Brey, E.M., Demian, N., Johnston, C.M., Dean, D., Jansen, J.A., Wong, M.E., and Mikos, A.G. Effect of biomaterial properties on bone healing in a rabbit tooth extraction socket model. J. Biomed. Mater. Res. 68A, 428, 2004.

19. Bancroft, G.N., Sikavitsas, V.I., van den Dolder, J., Sheffield, T.L., Ambrose, C.G., Jansen, J.A., and Mikos, A.G. Fluid flow increases mineralized matrix deposition in 3D perfusion culture of marrow stromal osteoblasts in a dose-dependent manner. Proc. Natl. Acad. Sci. USA 99, 12600, 2002.

20. Mooney, D.J., Sano, K., Kaufmann, P.M., Majahod, K., Schloo, B., Vacanti, J.P., and Langer, R. Long-term engraftment of hepatocytes transplanted on biodegradable polymer sponges. J. Biomed. Mater. Res. 37, 413, 1997.

21. Day, R.M., Boccaccini, A.R., Shurey, S., Roether, J.A., Forbes, A., Hench, L.L., and Gabe, S.M. Assessment of polyglycolic acid mesh and bioactive glass for soft-tissue engineering scaffolds. Biomaterials 25, 5857, 2004.

22. Colton, C.K. Implantable biohybrid artificial organs. Cell Transplant. 4, 415, 1995.

23. Canalis, E., Centrella, M., and McCarthy, T. Effects of basic fibroblast growth factor on bone formation in vitro. J Clin. Invest. 81, 1572, 1988.

24. Nagai, H., Tsukuda, R., and Mayahara, H. Effects of basic fibroblast growth factor (bFGF) on bone formation in growing rats. Bone 16, 367, 1995.

25. Mundy, G.R. Cytokines and growth factors in the regulation of bone remodeling. J. Bone Miner. Res. 8, S505, 1993.

26. Meriane, M., Charrasse, S., Comunale, F., and GauthierRouviere, C. Transforming growth factor beta activates Rac1 and Cdc42Hs GTPases and the JNK pathway in skeletal muscle cells. Biol. Cell 94, 535, 2002.

27. Saito, N., and Takaoka, K. New synthetic biodegradable polymers as BMP carriers for bone tissue engineering. Biomaterials 24, 2287, 2003.

28. Saito, N., Okada, T., Horiuchi, H., Ota, H., Takahashi, J., Murakami, N., Nawata, M., Kojima, S., Nozaki, K., and Takaoka, K. Local bone formation by injection of recombinant human bone morphogenetic protein-2 contained in polymer carriers. Bone 32, 381, 2003.

29. Kaito, T., Myoui, A., Takaoka, K., Saito, N., Nishikawa, M., Tamai, N., Ohgushi, H., and Yoshikawa, H. Potentiation of the activity of bone morphogenetic protein-2 in bone regeneration by a PLA-PEG/hydroxyapatite composite. Biomaterials 26, 73, 2005.

30. Laurencin, C.T., Attawia, M.A., Lu, L.Q., Borden, M.D., Lu, H.H., Gorum, W.J., and Lieberman, J.R. Poly(lactideco-glycolide)/hydroxyapatite delivery of BMP-2-producing cells: a regional gene therapy approach to bone regeneration. Biomaterials 22, 1271, 2001. 
31. Ruhe, P.Q., Kroese-Deutman, H.C., Wolke, J.G., Spauwen, P.H., and Jansen, J.A. Bone inductive properties of rhBMP2 loaded porous calcium phosphate cement implants in cranial defects in rabbits. Biomaterials 25, 2123, 2004.

32. Partridge, K., Yang, X., Clarke, N.M., Okubo, Y., Bessho, K., Sebald, W., Howdle, S.M., Shakesheff, K.M., and Oreffo, R.O. Adenoviral BMP-2 gene transfer in mesenchymal stem cells: in vitro and in vivo bone formation on biodegradable polymer scaffolds. Biochem. Biophys. Res. Commun. 292, 144, 2002.
Address reprint requests to: Antonios G. Mikos, Ph.D. Department of Bioengineering Rice University MS 142

P.O. Box 1892

Houston, TX 77251-1892

E-mail: mikos@rice.edu 